\title{
Uma nova espécie de Plagiometriona Spaeth, do Espírito Santo, Brasil (Coleoptera, Chrysomelidae, Cassidinae) ${ }^{1}$
}

\author{
Zundir José Buzzi ${ }^{2}$
}

\begin{abstract}
A new species of Plagiometriona Spaeth, Espirito Santo state, Brazil (Coleoptera, Chrysomelidae, Cassidinae). Plagiometriona (Plagiometriona) diffusa sp. nov. from Conceição da Barra, Espirito Santo State, Brazil, is described.

KEY WORDS. Coleoptera, Chrysomelidae, Cassidinae, Plagiometriona, new species
\end{abstract}

SPAETH (1899) criou o gênero Plagiometriona e nele incluiu várias espécies de Coptocycla Chevrolat, 1837 e descreveu uma espécie nova: $P$. eggi Spaeth, 1899 e em 1937, dividiu Plagiometriona em dois subgêneros Plagiometriona s. str. e Parametriona, o primeiro subdividido em seis e o segundo em onze grupos.

Plagiometriona (Plagiometriona) diffusa sp. nov. juntamente com P. seriata Spaeth, 1937 estão incluídas no segundo grupo de Plagiometriona, cujas espécies se caracterizam por terem a carena da epipleura atingindo a sutura elitral bem antes de atingir o ápice, o terceiro artículo das antenas aproximadamente duas vezes mais longo que o segundo e o clípeo tão largo quanto longo, com sulco médio longitudinal.

\section{Plagiometriona (Plagiometriona) diffusa sp. nov.}

\section{Figs1-2}

Em vista dorsal (Fig. 1) subarredondada, cerca de 1,07 vezes mais longa que sua maior largura (7,58 x 7,08 mm). Em vista lateral (Fig. 2) com forte giba dorsal; dali para frente caindo quase em linha reta até a margem anterior do pronoto e para traz, decaindo mais suavemente até pouco além do terço posterior dos élitros e depois mais abruptamente, até o ápice elitral. Coloração amarela, tendendo para o alaranjado. Cabeça com genas lisas e anteriormente com suave sulco longitudinal que se estende da área interalveolar até o vértice. Olhos pretos, cerca de duas vezes mais longos que sua maior largura $(0,80 \times 0,40 \mathrm{~mm})$ e quase tão longos quanto a altura da cabeça, medida da gula até o vértice $(1,00 \mathrm{~mm})$. Palpos labiais e maxilares com os artículos apicais bastante desenvolvidos e com aspecto globóide. Antenas com o artículo apical preto exceto a base e parte do ápice, amarelos; seis artículos basais brilhantes, com poucos e esparsos pêlos e os demais, densamente pilosos; todos os artículos de aspecto cilíndrico, medindo do primeiro ao último, respectivamente: $0,38-0,18-0,34-0,28-0,28-0,20-0,24-0,20-0,20-0,20-0,40 \mathrm{~mm}$.

1) Contribuição número 1257 do Departamento de Zoologia, Universidade Federal do Paraná.

2) Departamento de Zoologia, Universidade Federal do Paraná. Caixa Postal 19020, 81531-980 Curitiba, Paraná, Brasil. E-mail: zbuzzi@bio.ufpr.br 

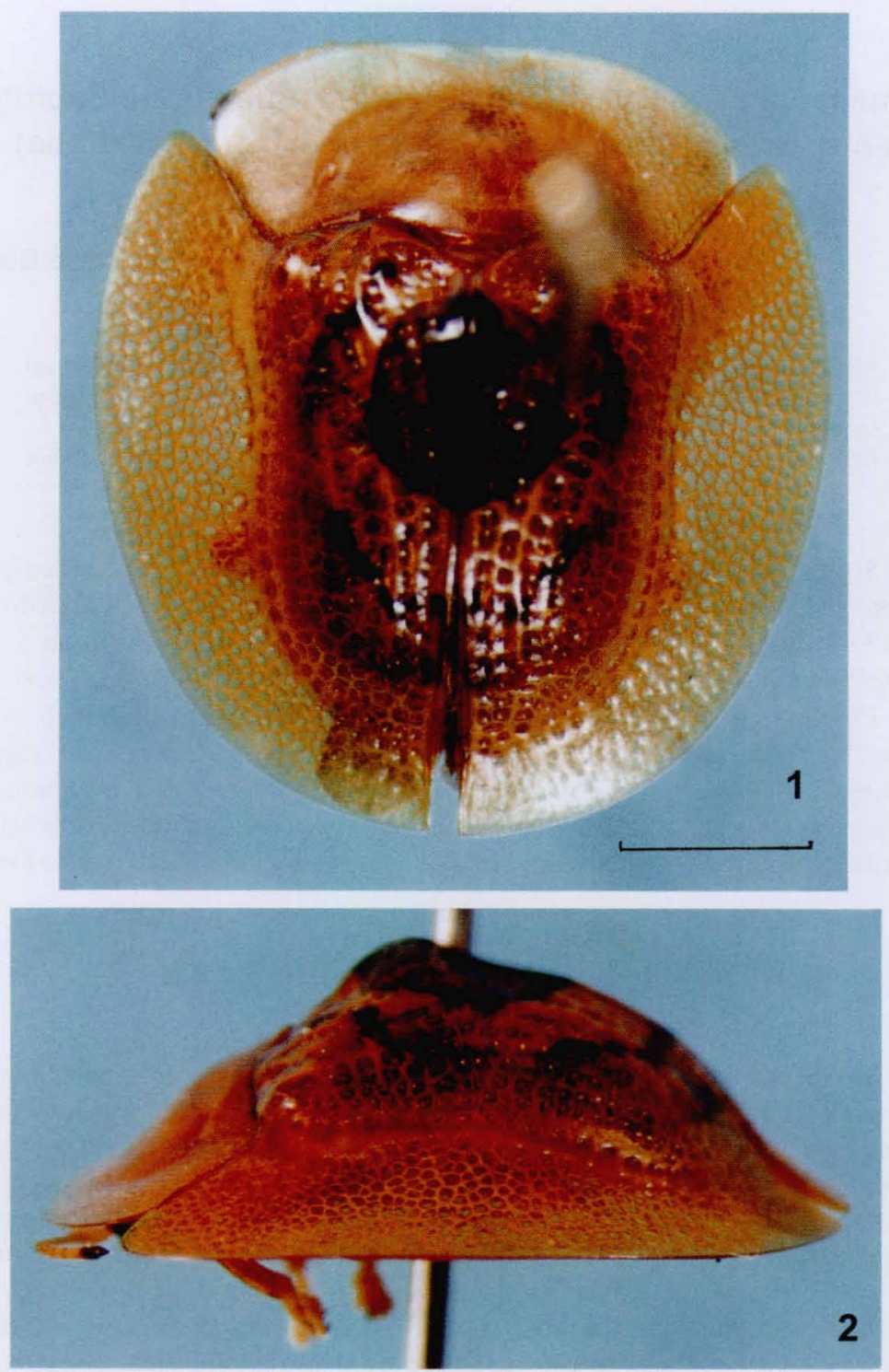

Figs 1-2. Plagiometriona diffusa sp. nov., holótipo. (1) Vista dorsal; (2) vista lateral. Escala: $1,8 \mathrm{~mm}$.

Pronoto trapezoidal, cerca de 1,8 vezes mais largo que seu comprimento mediano $(5,0 \times 2,8 \mathrm{~mm})$; abas transparentes, reticuladas; superfície microreticulada; no disco com poucos e esparsos pontos e aos lados, com curto sulco, em forma de meia-lua; projeção mediana posterior larga, pouco projetada e margem largamente arredondada e levemente elevada. Escutelo triangular; largura basal cerca de 1,5 vezes maior que seu comprimento mediano.

Revta bras. Zool. 19 (1): 995 - 997, 2002 
Fêmur anterior e mediano quase do mesmo comprimento e o da perna posterior, mais longo $(1,54 \times 1,56 \times 1,76 \mathrm{~mm})$; tíbia anterior mais longa que a média e mais curta que a posterior $(1,36 \times 1,24 \times 1,48 \mathrm{~mm})$.

Élitros com giba bastante forte; área anterior à giba com leve depressão; superfície discal densamente pontuada com os pontos em geral maiores que as interestrias; aba com forte retículo; na base, aos lados, projetada além do meio do pronoto e dali para traz, alargando-se suavemente até próximo ao meio, estreitando-se depois e no ápice, largamente arredondada; dorsalmente com mancha subarredondada, acastanhada, ao longo da sutura e posteriormente, preta. Entre a mancha dorsal e a linha discal, um estreito anel, de bordos não bem definidos, de coloração enegrecida; anteriormente e aos lados, interrompido. Posteriormente uma pequena mancha difusa, transversal, acastanhada, entre o anel e o ápice elitral.

Material examinado. Holótipo de Conceição da Barra, Espírito Santo, Brasil, 5-I-1970, C.T. \& C. Elias leg., depositado na Coleção de Entomologia Pe. Jesus Santiago Moure, Departamento de Zoologia da Universidade Federal do Paraná (DZUP), Curitiba, Paraná, Brasil.

Discussão. Plagiometriona (Plagiometriona) diffusa sp. nov. é facilmente identificada pelos desenhos dos élitros, principalmente pela mancha dorsal e o anel, com o aro muito estreito, que a circunda além da gibosidade dorsal e Plagiometriona seriata Spaeth, 1937 pelo anel fino, preto, duas vezes mais longo que largo e que abrange a parte posterior do pronoto e os élitros, não são gibosos.

\section{REFERÊNCIAS BIBLIOGRÁFICAS}

SPAETH, F. 1899. Beschreibung einiger neuer Cassididen nebst synonymischen Bemerkungen. III. Verh. zool.-bot. Ges. Wien 49: 213-221.

1937. Neue Cassidine des Rijksmuseums in Leiden und meiner Sammlung. Temminckia 2: $135-158$.

Recebido em 18.V.2001; aceito em 20.IX.2002.. 